\title{
Electrochemical Synthesis of Iron Oxide Nanoparticles for Biomedical Application
}

\author{
Cesar A C Sequeira* \\ Center of Physics and Engineering of Advanced Materials, Instituto Superior Técnico, University of Lisbon, Portugal
}

Submission: February 6, 2018; Published: February 19, 2018

${ }^{*}$ Corresponding author: Cesar AC Sequeira, Center of Physics \& Engineering of Advanced Materials, Instituto Superior Técnico, University of Lisbon, Portugal, E-mail: cesarsequeira@tecnico.ulisboa.pt

Abstract

Because of their magnetic and superparamagnetic properties, iron oxide nanoparticles (IONPs) have many potential applications for medical use. The synthesis of these nanoparticles (NPs) has been the basis of many studies, each proposing different synthesis methods yielding nanostructures of different properties. In this review the synthesis of biologically compatible IONPs by electrochemical deposition is described, thus exploring their potential use in biomedical applications. The chemical, physical and magnetic properties of these nanostructures are examined to determine their possible application in magnetic resonance imaging (MRI) contrast enhancement and thermal activation therapy. NPs characterization and demonstration of their potential uses pave the way to the development of smart magnetic IONPs for targeted diagnostics and therapeutics of human diseases, including cancer and Alzheimer's disease.

Keywords : Iron oxide Nanoparticles; Electrochemical Deposition; IONPs Biomedical Applications.

Abbreviations : IONP: Iron oxide Nanoparticle; NP: Nanoparticles; MNPS: Magnetite nanoparticles; TON : ON-time ; TOFF: OFF-Time; PRC: Pulsereverse current; PC: Pulse current; RDE : Rotating disc electrode; RRDE: Rotating ring disc electrode; EQCM: Electrochemical quartz crystal microbalance; TEM: Transmission electron microscopy; SEM: Scanning electron microscopy; STM: Scanning tunneling microscopy; AFM: Atomic force microscopy; ESTM: Electrochemical scanning tunneling microscopy; XRD: X-ray diffraction; XPS: X-ray photoelectron spectroscopy; TDD:

Targeted drug delivery; QD: Quantum dots

\section{Introduction}

An iron oxide nano particle (IONP), in nanotechnology, is a particle defined as a small object that behaves as a whole unit in terms of its transport and properties. Particles are further classified according to size: in terms of diameter, fine particles cover a range between 100 and 2500 nanometers. On the other hand, ultrafine particles and Nanoparticles (NPs) are sized between 1 and 100 nanometers. Nanoparticles may or may not exhibit size-related properties that differ significantly from those observed in fine particles or bulk materials [1].

Although the size of most molecules would fit into the above outline, individual molecules are usually not referred to as Nanoparticles. Nanoclusters have at least one dimension between 1 and 10 nanometers and a narrow size distribution. Nanopowders are agglomerates of ultrafine particles, nanoparticles, or nanoclusters [2]. Nanometer-sized single crystals, or single-domain ultrafine particles, are often referred to as nanocrystals. Nanoparticle research is currently an area of intense scientific interest due to a wide variety of potential applications in biomedical, optical, electronic and other fields.

Iron oxides are one of the most important transition metal oxides of technological importance. Sixteen pure phases of iron oxides, i.e., oxides, hydroxides or oxy-hydroxides are known to date. These are $\mathrm{Fe}(\mathrm{OH})_{3}, \mathrm{Fe}(\mathrm{OH})_{2}, \mathrm{Fe}_{5} \mathrm{HO}_{8} \cdot 4 \mathrm{H}_{2} \mathrm{O}, \mathrm{Fe}_{3} \mathrm{O}_{4}, \mathrm{FeO}$, five polymorphs of $\mathrm{FeOOH}$ and four of $\mathrm{Fe}_{2} \mathrm{O}_{3}$. Characteristics of these oxide compounds include mostly the trivalent state of the iron, low solubility and brilliant colors [3]. All the iron oxides are crystalline except Schwertmannite and ferrihydrite which are poorly crystalline. These oxides can be synthesized by all known wet chemical methods but to tailor the particle size in nano range and morphology towards a particular application still remains a challenging task. Some of the synthesis techniques include chemical precipitation, sol-gel, hydrothermal, surfactant mediated-precipitation, emulsion-precipitation, microemulsionprecipitation, electrodeposition, and micro wave assisted hydrothermal, surfactant mediated-precipitation, oxides find applications as catalysts, sorbents, pigments, flocculants, coatings, gas sensors, ion exchangers and for lubrication [4-9].

Iron oxide nano-composites have potential applications in areas such as magnetic recording, magnetic data storage devices, toners and inks for xerography, and magnetic resonance imaging, wastewater treatment, bioseparation, and medicine [10-18]. Below a critical size $\mathrm{Fe}_{2} \mathrm{O}_{3}$, nanoparticles can be used 
for niche applications like transparent iron oxide pigments, due to their durability, shade, UV absorption and added value [19]. Careful control of the preparation process of transparent iron oxide pigments results in the formation of pigments with very small primary particle sizes. When fully dispersed, they do not scatter light and are hence completely transparent. A brief literature scan is reported in the present review considering the application of various forms of nano iron oxides in the above fields.

One of the most important iron oxide, black in color and ferromagnetic, is Magnetite $\left(\mathrm{Fe}_{3} \mathrm{O}_{4}\right)$ which contains both $\mathrm{Fe}$ (II) and $\mathrm{Fe}$ (III). Although stoichiometric magnetite has Fe (II)/ Fe (III) equals to 0.5 but magnetite, which is frequently nonstoichiometric results in a $\mathrm{Fe}^{3+}$ deficient layer. Magnetite has an inverse spinel crystal structure with a face-centered cubic unit cell having an edge length of $0.839 \mathrm{~nm}$ and 32 oxygen atoms. In this particular crystal structure $\mathrm{Fe}^{2+}$ and half of the $\mathrm{Fe}^{3+}$ occupy octahedral sites and the other half of the $\mathrm{Fe}^{3+}$ occupies tetrahedral sites. Divalent iron atoms prefer to take octahedral sites to obtain higher crystal field stabilization energy. However, the trivalent iron atoms occupy the two octahedral and tetrahedral sites (crystal field stabilization energy $=0$ ). The actual crystal types of magnetite consist of octahedron and rhombodecahedron with surface area in the range of 4 to $100 \mathrm{~m}^{2} \mathrm{~g}^{-1}$.

Magnetite has been attracting attention in the biomedical applications because of its biocompatibility and low toxicity in the human body [20,21]. Also magnetite has been used as a catalyst for many reactions of important industrial productions such as the $\mathrm{NH}_{3}$ production, alcohol oxidation, and FisherTropsch synthesis for hydrocarbons and it can catalyse oxidation/reduction reactions [22-26]. On the other hand, magnetite was used in pigment and related industries [27]. Iron oxide (magnetite) can also be used in wastewater purification [28]. It can be an absorbent for heavy metal from water [29]. The synthesis of iron oxide nanoparticles of controlled shapes has attracted much attention because the physical and chemical properties depend strongly on particles size and morphology. As reported above, recently several chemical methods are employed to synthesize iron oxide nanoparticles such as sol-gel, hydrothermal, solid state, wet milling, pyrolysis and microemulsion [30-37]. The synthesis method plays a key role in determining the morphology, particles sizes, and shape.

On the other hand, the electrochemical methods are used to synthesize different nanostructured materials, such as Palladium, $\mathrm{SnO}_{2}$, and super- hydrophilic polypyrrole [38-40]. Cyclic voltammetry, potentiostatic, galvanostatic and pulsed current as different electrochemical techniques were used to synthesize nanoparticles [41-51]. Many reports that show pulsed current routes present a simple, quick, and economical method for the preparation of various types of nanoparticles. In previous studies, we successfully applied electrochemical techniques to synthesize nanoparticles, nano fibers, nanorods and nanoclusters. These nanomaterials have been used for the fabrication of high performance electrodes for water electrolysers, low temperature alkaline fuel cells and other energy devices [52-65].

Recently, based on experience gained with the preparation of nanoparticles electrocatalysts for energy applications, we initiated preliminary studies of electrosynthesis of iron oxide nanoparticles, motivated by their biomedical applications. The effects of experimental parameters of the electrosynthesis such as imposed cell current, imposed cell potential, interelectrode distance, dc pulse, pulse time, pulse height, relaxation time, pulse frequencies, number of pulse cycles, solution temperature, $\mathrm{pH}$, electrolyte concentration, synthesis additives and so on are being investigated in order to find the optimum conditions to synthesize iron oxides, and particularly, magnetite nanoparticles. In this context, the present short article outlines the electrochemical method to synthesize iron oxides in the nano range for biomedical applications.

\section{Electrochemical Synthesis}

Electrochemical method has been utilized to generate different iron oxide nanoparticles phases like maghemite and magnetite nanoparticles. An electrochemical synthesis can be basically interpreted by passing an electric current between two or more elctrodes which is called the anode and cathode located in an electrolyte. In this technique, the anode can be oxidized to metal ion species in the electrolyte and the metal ion is later on reduced to metal by the cathode with the assistance of stabilizers. In fact, the synthesis occurs at the interface of electrode-electrolyte. Here, several characteristics of electrosynthesis method will be introduced which differentiate it from other generation techniques. Electrochemical synthesis method occurs near to the electrode in the electric double layer, owning high potential gradient $\left(105 \mathrm{Vcm}^{-1}\right)$.

According to these conditions, electrochemical reactions usually give rise to products which is not possible to gain from a chemical synthesis. The product is deposited on the electrode normally in the forms of a coating or a thin film. Additionally, a solid-liquid interface favors the growth of coatings on substrates with different morphology. Therefore, if a properly-shaped counter electrode is applied, a uniform polarization is obtained. This method doesn't require high temperature and should not exceed over the electrolyte's boiling point. Kinetic control can be employed by adjusting the current passed through the cell, even though thermodynamic control can be applied by changing the cell potential. Since electrochemical synthesis method is based on an oxidation/reduction reaction, by altering and adjusting the cell potential, the oxidizing or/ and reducing power can be constantly fluctuated and appropriately selected - which cannot be accessible by other methods in chemical synthesis. The film structure can be controlled by changing the bath composition and experiments are effortless to run and the instruments are cost effective and easily available. 
It should be noted that the standard electrode potential for an electrochemical reaction is the potential where the rate of the reduction and the oxidation reactions are equal at standard conditions of concentrations, pressure and temperature. The Nernst equation relates the standard electrode potential $\mathrm{E}^{0}$ to the electrode potential E:

$$
E=E^{0}+\frac{R T}{n F} \ln \frac{\{o x\}}{\{r e d\}}
$$

where $\mathrm{R}$ denotes the standard gas constant $\left(8.314510 \mathrm{JK}^{-1}\right.$ $\mathrm{mol}^{-1}$ ), $\mathrm{T}$ the absolute temperature in Kelvin, $\mathrm{n}$ the number of electrons transferred and $\mathrm{F}$ the Faraday's constant $(96485.309$ $\mathrm{C} \mathrm{mol}^{-1}$ ). The potential also depends on the ratio of the natural logarithm of the activities of the oxidized and reduced species. The mass deposited on the working electrode during the electrolysis is proportional to the number of moles of electrons transferred, as is stated by Faraday's law of electrolysis:

$$
m=\frac{Q M}{n F}
$$

where $\mathrm{m}$ is the mass of the deposit produced at the electrode (in grams) and $Q$ is the total electric charge (in coulombs) required for the process.

The electrolysis of species can be performed using a constant current forced trough the electrochemical cell, while the electric potential is monitored. Alternatively, a desired potential can be chosen, which is then maintained by the instrument while the necessary current used to maintain that potential is monitored. Apart from galvanostatic on potentiostatic electrolysis, successful electrosynthetic reactions can also be obtained by pulse current or exerting other power supply current waveforms. Experimental results reported in the literature showed that the pulsed current method is a confident and controllable method to synthesize metal oxide nanoparticles [66]. For a proper design of electrochemical synthesis or electrodeposition we also need to make a proper choice of electrolyte and its composition, as well as a suitable $\mathrm{pH}$, temperature, and electrolyte concentration. Possibility to choose inert or reactive electrodes, and divided or undivided cells, is also important.

The electrode potential is directly connected to the energy change of the electrode process through the relationship: $\Delta G^{0}=-n F E^{0}$ When the electrode potential is made more negative in relation to the standard reduction potential for an electrochemical reaction, the reduction current increases because the rate of electron transfer of the reduction increases. In the electron transfer controlled potential region, there is a linear relationship between the potential and the logarithm of the deposition current known as the Tafel linearity. However, the current can also be limited by other factors such as mass transfer, preceding chemical steps and crystallization processes.

In an electrochemical cell the current forced through the solution is carried by ions. The consumption of species during the reduction at the working electrode gives rise to a concentration gradient in the solution outside the electrode surface. The random motion of the species by which this concentration difference is equalized is called diffusion. In an unstirred solution the diffusion layer thickness extends into the solution until vibration and thermal movement start to contribute to the mass transport. The mass transport of ions also takes place by migration, which is the movement of charged particles in an electric field. The contribution of migration to the mass transport of electoactive species is usually diminished by the addition of inert ions that carry the current but do not participate in the electrode reactions.

The rate of the electrode reactions depends on chemical reactions preceding or following the electron transfer, the electron transfer kinetics and surface reactions, such as adsorption and crystallization steps [67]. The current is generally limited either by the mass transport of species towards the electrode or by kinetics of the electrode reaction. If one wants to study the kinetics of an electrode reaction, care must be taken to prevent problems with the mass transport of the species. This can be achieved by forced convection of the solution using the rotating disc electrode (RDE) technique. On the other hand, determinations of the diffusion coefficient of species in the solution by electrochemical methods require that the kinetics of the electrode reaction does not limit the current.

When an electrochemical experiment is performed using a constant current, the potential shifts to the value required to maintain that current. Under conditions of mass transfer control (i.e. when the kinetics of the electrode reaction does not limit the current), the potential shifts when the concentration of electroactive species at the electrode surface is reduced to zero. The time needed for this depletion of the species, the transition time $\tau$, is given by the Sand equation:

$$
\tau^{1 / 2}=\frac{n F(\pi D)^{1 / 2} C^{*}}{2 I}
$$

where I is the current (in $\mathrm{mA}$ ), $\mathrm{C}^{*}$ is the bulk concentration (in $\mathrm{mol} / \mathrm{cm}^{3}$ ), and D is the diffusion coefficient expressed in $\mathrm{cm}^{2}$ / $s^{1}[67]$.

Positively charged metalions are Lewis acids and many organic molecules form stable coordination compounds with metal ions in which oxygen or nitrogen are the electron donor atoms [68]. The formation of stable complexes enables deposition under kinetic (or activation) control, which generally results in smooth deposits [69]. Complexes are also often used for alloy deposition since the reduction potentials of two metal ions then can be brought together by the proper choice of complexes. Deposition from alkaline solution is generally made possible by ligands forming soluble complexes with metal ions. Hydroxycarboxylic acids form very stable complexes with metal ions where both the carboxylic and the alcoholic hydroxyl groups take part in complex formation [70]. When these acids are liberated from the complexes with the metal ion upon electrochemical deposition, the hydroxyl groups are reprotonated again because of the small dissociation constants of these acids. This consumption of $\mathrm{H}^{+}$(or generation of $\mathrm{OH}^{-}$) leads to a local rise in the $\mathrm{pH}$ value when the buffer capacity of the solution has been consumed. 
Electrochemical deposition from complexes of hydroxycarboxylic may therefore induce local precipitation of hydroxides or oxides. The reductive electrochemical deposition of metals from aqueous solutions is a well- established field [71]. The optimum current density for the deposition of compact coatings is generally that corresponding to the end of the Tafel linearity range, as the nucleation rate increases with more negative potentials but mass Transport limitations causes irregular growth [72]. Additives are commonly used in plating baths to improve the adhesion and material properties of the metal deposits. Levelling agents are organic molecules that adsorb on the surface and accelerate the rate of the deposition within trenches, thus enabling depositions of smooth and bright deposits $[73,74]$. Tartrate has for example been used in tin and copper deposition [75].

The deposition of metal oxides from aqueous solutions is mainly performed in alkaline solutions containing metal complexes. Electrochemical deposition of metal oxides can be carried out under oxidizing conditions as well as reducing conditions from alkaline solutions. In both cases, the metal ion dissociates from the complex and precipitates on the electrode as the oxide. What controls the ability to deposit an oxide is the stability of that oxide under the experimental conditions, i.e. the potential, temperature and $\mathrm{pH}$. Deposition of oxides under reductive conditions includes the reduction of metal ions that form stable oxides. The $\mathrm{Cu}$ (I) oxide, $\mathrm{Cu}_{2} \mathrm{O}$, has thus been demonstrated to be deposited from alkaline $\mathrm{Cu}$ (II) solutions containing various ligands [76,77]. Otherwise cathodic deposition of metal oxides relies on precipitations due to electrochemically induced local $\mathrm{pH}$ alterations. Reduction of dissolved oxygen or nitrate ions results in local production of hydroxide ions, which for example enables the deposition of $\mathrm{CdO}$ and $\mathrm{ZnO}$ [78-80]. However, hydroxide ions are also produced upon the dissociation of complexes with ligands like lactic, tartaric and citric acid containing $\beta$ - hydroxyl groups [81].

Nanostructured materials have been extensively studied during the last decade due to their interesting electronic, magnetic, electrochemical and optical properties and potential use as catalytic- and electrode materials in various devices. Nanocrystalline metals and alloys have been achieved using pulses of high current density [82]. Nanocrystalline metal oxides have been prepared using oxidizing conditions in a non-aqueous medium [83]. Multi-layered structures of transition metals are quite common, as for example $\mathrm{Co} / \mathrm{Cu}$ multilayer's and $\mathrm{Ni} / \mathrm{Co}$ multilayer's [84,85]. Multilayers of $\mathrm{MoS}_{2}$ have been deposited using an electrochemical/chemical synthesis method [86]. Magnetic multilayer's of metal/netal-oxide have been produced electrochemically by deposition of the metal followed by anodic oxidation, as for example for Fe/Fe-oxide [87], Well-ordered structures of various oxides and chalcogenides including $\mathrm{CdTe}$, CdSe, CdS, ZnO, ZnSe, $\mathrm{Tl}_{2} \mathrm{O}_{3}, \mathrm{PbO}_{2}, \mathrm{Cu}_{2} \mathrm{O}, \delta-\mathrm{BiO}_{3}, \mathrm{Fe}_{3} \mathrm{O}_{4}, \mathrm{PbSe}$ and $\mathrm{PbS}$ ) have been synthesized by electrochemical epitaxy on metallic substrates (platinum and gold) or crystalline $\mathrm{TiO}_{2}, \mathrm{Si}$, InP, GaAs, GaN [88].
Layered nanostructures of iron-group alloys have also been deposited under current oscillations arising from adsorption/desorption of electrolyte components [89]. A facile electrochemical method was suggested by M Starowicz et al. [90] describing the synthesis of magnetic nanoparticles mostly maghemite phase. The reaction was processed in $\mathrm{LiCl}$ solution in the presence of ethanol and water. The round shape nanoparticles with an average size between 5 and $40 \mathrm{~nm}$ were obtained which was adjusted through water-to- ethanol ratio. D Gopi et al. [91] reported electrochemical synthesis of superparamagnetic cubic magnetite nanoparticles (MNPS). The cubic magnetite nanoparticles have been generated by electrooxidation of iron in aqueous medium of ferrous perchlorate. This results in uniform particles with size of $15 \pm 6 \mathrm{~nm}$. These results show the possibility of surface plasmon resonance effect in the iron oxide nano particles while no micelles or stabilizing agent or surfactant was applied to avoid formation of cluster growth.

A vibrating sample magnetometer spectrum was also recorded for magnetite nanoparticles synthesized by electrochemical method at $0.1 \mathrm{M}$ concentration of $\mathrm{Fe}\left(\mathrm{ClO}_{4}\right)_{2}$ at $50 \mathrm{~mA} \mathrm{~cm}^{-2}$. The hysteresis curve demonstrated the super paramagnetic property of the magnetite nanoparticles at room temperature and it showed a very less coercive field (50 G). The applied magnetic field is in the range of $-15,000$ to 15,000 Gauss while the magnetization is not saturated in this applied magnetic field which is terminated at $27 \mathrm{emu} \mathrm{g}^{-1}$ [92]. C Pascal et al. studied the generation of $-\mathrm{Fe}_{2} \mathrm{O}_{3}$ nanoparticles with an electrochemical method using an organic medium. The particle size was instantly supervised by the employed current density. In addition, use of cationic surfactants resulted in enhancing the stability of the particles which led to formation of colloidal suspension. The average particles ranging in 3-8 $\mathrm{nm}$ caused a narrow particle size distribution.

Mossbauer spectroscopy and magnetization measurements displayed that the nano-powders possess superparamagnetic property at ambient. S Franger et al. [93] reported pure, homogeneous and ultrafine magnetite particles synthesized by the electrochemical technique at ambient using a Fe electrode which was submerged in an alkaline medium consisting of complexing compounds. $\mathrm{Fe}_{3} \mathrm{O}_{4}$ nanoparticles were prepared through a novel process originated from electro- precipitation in ethanol by M Ibrahim et al. [94]. The prepared nanoparticles had an average mean size centered on $6.2 \mathrm{~nm}$ with a quite narrow distribution. However, nanoparticles have shown strong tendency towards the agglomeration due to the freesurfactant production. In the last decade many more studies for the electrochemical deposition of iron oxide thin films were reported; these films were both cathodically and amodically electrodeposited [95-103].

In the case of anodic formation of iron oxides, the different phases of the iron oxides- oxyhydroxides thin films were obtained by adjusting deposition potentials and solutions composition. Zotti et al. [101]. reported the cathodic electrodeposition of 
amorphous $\mathrm{Fe}_{2} \mathrm{O}_{3}$ thin films by reduction of Fe (III) perchlorate in oxygenated acetonitrile where ferric ions reduced with dissolved oxygen to form amorphous $\mathrm{Fe}_{2} \mathrm{O}_{3}$. Amorphous $\mathrm{Fe}_{2} \mathrm{O}_{3}$ thin films were later converted to $\alpha-\mathrm{Fe}_{2} \mathrm{O}_{3}$ (i.e. hematite) thin films after heat treatment. Schrebler et al. [102] electrodeposited amorphous and nanocrystalline $\alpha-\mathrm{Fe}_{2} \mathrm{O}_{3}$ (i.e. hematite) thin films from electrolytes containing $5 \mathrm{mM} \mathrm{FeCl}_{3}+\mathrm{lM} \mathrm{H}_{2} \mathrm{O}_{2}+5 \mathrm{mM}$ $\mathrm{KF}+0.1 \mathrm{M} \mathrm{KCl}$ at $50 \mathrm{C}$. The reduction of hydrogen peroxide at the cathode caused an increase in local pH on the surface of the cathode which later directed the surface precipitation of $\mathrm{Fe}(\mathrm{OH})_{3}$. Ferric hydroxides were later transformed to $\mathrm{Fe}_{2} \mathrm{O}_{3}$ by thermal annealing in air. Favier et al. [103] synthesized amorphous maghemite nanoparticles by anodic dissolution of a sacrificial Fe anode, followed by chemical reaction in an organic medium.

The formation mechanism for synthesis of $\mathrm{Fe}_{3} \mathrm{O}_{4}$ nanoparticles by the electroprecipitation route can be explained assuming that the electrolyte bath contains iron (III), nitrate ions and water under high current density. Initially the reduction of water and nitrates generates $\mathrm{OH}$ - ions at the cathode

$$
\begin{aligned}
\mathrm{NO}_{3}^{-}+\mathrm{H}_{2} \mathrm{O}+2 e^{-} & \rightarrow \mathrm{NO}_{2}^{-}+2 \mathrm{OH}^{-} \\
2 \mathrm{H}_{2} \mathrm{O}+2 e^{-} & \rightarrow \mathrm{H}_{2}+2 \mathrm{OH}^{-}
\end{aligned}
$$

The $\mathrm{pH}$ enhances near the cathode and leads to $\mathrm{Fe}(\mathrm{OH})_{3}$ to precipitate. Then, the $\mathrm{Fe}(\mathrm{OH})_{3}$ is reduced to magnetite $\left(\mathrm{Fe}_{3} \mathrm{O}_{4}\right)$ based on the reaction.

$$
2 \mathrm{Fe}(\mathrm{OH})_{3}+e^{-} \rightarrow \mathrm{Fe}_{3} \mathrm{O}_{4}+4 \mathrm{H}_{2} \mathrm{O}+\mathrm{OH}^{-}
$$

It should be taken into account that reaction (6) re-produces the water, which was applied in reduction of water and nitrate ions. Note also, that reaction (6) represents that magnetite nanoparticles are not produced due to extra water existence in the solution, and $\mathrm{Fe}(\mathrm{OH})_{3}$ continues being stable [94]. In iron electro oxidation similar reactions can also be taken place. At the beginning of the reaction, at the anode, iron was oxidized first to ferrous ions and then to ferric ions due to high i or E imposed.

$$
\begin{gathered}
\mathrm{Fe} \rightarrow \mathrm{Fe}^{2^{+}}+2 e^{-} \\
\mathrm{Fe}^{2^{+}} \rightarrow \mathrm{Fe}^{3^{+}}+e^{-}
\end{gathered}
$$

Another reaction that takes place and provides protons to the proximities of the anode is the electrolysis of water according to reaction:

$$
\mathrm{H}_{2} \mathrm{O} \rightarrow 2 \mathrm{H}^{+}+2 e^{-}+1 / 2 \mathrm{O}_{2}
$$

At the cathode the reduction of water takes place as presented in Equation 5. Since pH of the solution was not initially high but increases during Equation 5, the precipitation of ferric hydroxide (brown solution) occurs during the first minutes of process following reaction.

$$
\mathrm{Fe}^{3^{+}}+\mathrm{OH}^{-} \rightarrow \mathrm{Fe}(\mathrm{OH})_{3}(s)
$$

The $\mathrm{OH}$ - ions produced at the cathode (5) arrive to the anode's surface by diffusion, proportioning the basic medium necessary for the iron hydroxide to be formed. Ferric hydroxide can now react in two different ways. If the $\mathrm{pH}$ of the solution is not basic enough, it may dehydrate to generate a non- magnetic ferric oxide. However, if the $\mathrm{pH}$ is around 8 or 9, ferric hydroxide can be reduced at the cathode to form $\mathrm{Fe}_{3} \mathrm{O}_{4}$ as represented in the following equation [94]:

$$
3 \mathrm{Fe}(\mathrm{OH})_{3}(s)+\mathrm{H}^{+}+e^{-} \rightarrow \mathrm{Fe}_{3} \mathrm{O}_{4}(s)+5 \mathrm{H}_{2} \mathrm{O}
$$

Considerations above show that among all synthetic methods, prospects for electrochemical synthesis of iron oxide nanoparticles seem very promising. However, some challenges need to be dealt to fulfill novel efficient and unique iron oxide nanoparticles. In electrochemical nanosynthesis, factors affecting the electrodeposits such as surface preparation, physical and chemical nature of substrate surface, deposition temperature, deposition current/deposition potential, bath composition and concentration, power supply current waveform, etc., play an important role in the reaction. The ingredients of a plating bath are the metal salt solution which provides a source of the metal or metals being deposited, and various additives. At least, there are five purposes for the additives: to form complexes with ions of the depositing metal; to provide conductivity; to stabilize the solution, e.g. against hydrolysis; to act as a buffer to stabilize the $\mathrm{pH}$; and to modify or regulate the physical form of the deposit.

Another key factor affecting the electrodeposits is the type of applied current. Usually two types of current are used: direct current plating; and pulse plating. In dc-plating, constant current is used, and the rate of arrival of metal ions depends on their diffusion coefficient (electrode-to-part spacing and agitation). The pulse current (PC) and pulse-reverse current (PRC) are used to get the deposit with reduced porosity, and finer grains, and to minimize the use of additives and, contamination, etc.; [in PC conditions, all the pulses are in one direction (with no polarity), and each pulse consists of an ON-time (TON) during which potential/current is applied, and an OFF-Time (TOFF) during which zero current is applied]. The morphology of some metal and alloy deposits were found to be superior to the dc-plated deposits [104-108].

\section{Nanoparticles Characterization}

Commonly used techniques for the study of electrochemical deposition are various electrochemical methods: cyclic voltammetry, potential step methods and controlled-current techniques. In cyclic voltammetry, the current is recorded as the potential is swept between two potentials causing reduction and oxidation of species. The shape of the voltammogran gives information about the redox potential, and the occurrence of diffusion limitation or surface confined reactions. Varying the potential scan rate, which set the time-scale of the experiment, can test the reversibility of the electrochemical reaction. When a constant potential is applied, the current is measured as a function of time. Potential step (chronoamperometric) methods are used to determine diffusion coefficients and the concentrations of electro active species. The shape of the current-time curves can also give information about the type of nucleation taking place during the electrochemical deposition [109]. 
When a constant current is forced through an electrochemical cell, the potential takes on the value necessary to enable an electrochemical reaction to keep up with the current. Controlled current techniques are used among other things to study multicomponent systems and multistep reactions because the measured potential changes as the surface concentration of electroactive species decreases sufficiently. The galvanostatic double pulse method can be used to determine rate constants of very rapid electron transfer reactions. The thickness of a metal film can be determined by oxidation using a constant current. The rotating disc electrode (RDE) is used for measurements under conditions of controlled mass transport of the reacting species. The technique is also being used to study the influence of mass transport during spontaneous potential oscillations. The rotating ring disc electrode (RRDE) is often used for the detection of reaction intermediates [67]. However, the latter technique requires more sophisticated and expensive equipment in the form of a bipotentiostat. RDE and RRDE methods are also being applied to develop an understanding of the reaction mechanism for the deposition of metal oxides [110].

A powerful and very valuable tool in electrodeposition studies is the electrochemical quartz crystal microbalance (EQCM) technique-. A gold-coated quartz crystal is then used as the working electrode in a conventional three electrode setup. The quartz crystal frequency is continuously measured, allowing in-situ detection of mass changes of the working electrode. The detection of mass changes enables the determination of charge efficiencies during electrochemical depositions. The EQCM technique relies on the converse piezoelectric effect where an applied electric field induces shear deformation of a thin quartz wafer, prepared from a special angle of cut with respect to the crystallographic axis of the quartz crystal [111]. An alternating potential across the quartz crystal causes a vibrational motion with amplitude parallel to the surface of the crystal that results in a transverse acoustic wave. Deposition of a layer on top of the quartz crystal increases the thickness of the resonator and results in a longer acoustic wavelength. The measured frequency of the wave thus decreases according to the Sauerbrey equation:

$$
\Delta f=-2 f_{0}^{2} \Delta m / A\left(\mu_{q} \delta q\right)^{1 / 2}
$$

where $f_{0}$ is the frequency of the bare quartz crystal, $\Delta \mathrm{m}$ is the mass change, $\mathrm{A}$ is the electrode area, $\mu \mathrm{q}$ is the shear modulus and $\delta_{\mathrm{q}}$ is the density of quartz. The Sauerbrey relationship requires that the deposited material is a rigid and very thin film on the surface of the shear wave antinode [67]. Factors that lead to nonideal behaviour include viscoelastic effects, high mass loadings, surface roughness, surface stress, interfacial slippage and nonuniform mass distribution [111]. The technique was used for the interpretation of potential and current curves, the determination of layer thickness, and the detection of codeposition of oxide. An EQCM experimental setup including hydrodynamic control has also been used for studies of phase composition quantification of electrodeposited ternary chalcogenide compounds [112].
Structural information concerning materials can be obtained by scanning probe techniques such as transmission electron microscopy (TEM), scanning electron microscopy (SEM), scanning tunneling microscopy (STM) and atomic force microscopy (AFM). The latter techniques allow examinations of electrode surfaces in air, as well as in solution during experiments. STM measures the tunnelling current between the surface and a tip and has, for example, been used for the structural characterization of many metal surfaces. STM has also been used for studies of nanoscale electrodeposited super lattices [113]. Atomic force microscopy (AFM) is used to create a map of the surface topography on a micrometer scale by scanning a small tip over the surface. AFM has been used for the study of structures, sizes, shapes and aggregation of iron oxide nanoparticles [114].

The morphology and nucleation kinetics of iron oxide nanoparticles synthesize by decomposition of an organometallic precursor was recently studied using in-situ and ex-situ TEM [115]. A very valuable technique is the electrochemical scanning tunnelling microscopy (ESTM), which measures the tunnelling current during an electrochemical experiment. Several studies on the initial stages of oxidation of iron in alkaline solution have been performed with ESTM [116]. Mapping of the electrochemical activity can be achieved by measurements of the current caused by an electrochemical reaction, using a technique called scanning electrochemical microscopy (SECM) [117]. The latter technique can also be used for localized electrochemical deposition, as was demonstrated for iron microstructures [118]. The technique of scanning electron microscopy (SEM) uses the detection of secondary electrons generated in the sample by an electron beam of high intensity. An image of the sample is created by the topographic contrast that arises due to variations of the intensity of electrons that reach the detector from different points of the sample surface [119]. SEM is nowadays a standard analysis technique and was recently used for studies of iron crystallization $[120,121]$.

Spectroscopic techniques commonly used to study electrochemical interfaces include ultraviolet and visible spectroscopy, vibrational spectroscopy, electron- and ion spectrometry and X-ray methods [67]. A powerful technique for the in-situ study of electrode surfaces is synchrotron X-ray diffraction [122]. X-ray diffraction (XRD) is based on the diffraction phenomenon that arises when electromagnetic radiation (light) with a wavelength of the order of interatomic distances interacts with crystalline (ordered) material [123]. In X-ray photoelectron spectroscopy (XPS), the kinetic energy of electrons leaving the sample is measured, providing elemental identification and information about the bonding character by detection of chemical shifts in the binding energy of the electrons [124]. XPS is commonly used for surface analysis and was recently used for studies of the deposition of iron $[125,126]$. The technique of Raman spectroscopy uses a monochromatic laser beam to create vibration and rotation movement of molecules in solution or vibrations in solid matter [127]. A small fraction 
of the scattered light emerges with a change in frequency and is detected by a CCD camera [127]. The technique was recently used for the study of levelers for Fe electrodeposition from acidic sulphate solution [128].

Ellipsometry is based on the rotation of plane-polarized light during interaction of matter [129]. Since the electrode surface changes during an electrochemical experiment, the technique is well- suited for in-situ studies of surfaces [67]. The technique was recently used for the study of adsorption of surfactants on iron $[130,131]$.

\section{Biomedical Applications}

Various applications of iron oxides/hydroxides/ oxyhydroxides in nano form can be attributed to the difference in behaviour of particles in nano scale as compared to their bulk counterparts. The nano particles usually have much larger surface area due to their smaller size and can reduce the volume required to achieve same effect when used as a catalyst. In case of mitigation of anions/cations from aqueous solutions, iron oxides in nano form will have higher number of active sites for adsorption, thereby reducing the amount required per liter of solution. The adsorption process involves surface hydroxyl group interaction with adsorbents. Nano iron oxides exhibit very different magnetic properties which can be used for soft ferrites and biomedical applications including drug delivery and magnetic resonance imaging. Down to the nanoscale, super paramagnetic iron oxide nanoparticles can only be magnetized in the presence of an external magnetic field, which makes them capable of forming stable colloids in a physio-biological medium. Their super paramagnetic property, together with other intrinsic properties, such as low cytotoxicity, colloidal stability, and bioactive molecule conjugation capability, makes such nano magnets ideal in both in-vitro and in vivo biomedical applications [132].

In the context of invivo applications, IONPs have a large surface area and can be engineered to provide a large number of functional groups for cross-linking to tumor-targeting ligands such as monoclonal antibodies, peptides, or small molecules for diagnostic imaging or the delivery of therapeutic agents [133]. Especially, the magnetic properties of IONPs can be used in numerous in vivo applications, which can be divided into three main groups:

a) magnetic vectors that can be directed by means of a magnetic field gradient towards a certain location, such as in the case of targeted drug delivery;

b) magnetic contrast agents in MRI;

c) Hyperthermia or thermoablation agents, where the magnetic particles are heated selectively by application of a high- frequency magnetic field; the most important in vivo applications are therapeutic (hyperthermia and drugtargeting) and diagnostic (nuclear magnetic resonance NMR, imaging) [134-143].
Targeted drug delivery (TDD) seeks to concentrate the medication in the tissues of interest while reducing the relative concentration of the medication in the remaining tissues and crossing the biological barriers by active accumulation or an active targeting strategy [135]. Furthermore, magnetic IONP based drug targeting is a promising cancer treatment method for avoiding the side effects of conventional chemotherapy by reducing the systemic distribution of drugs and lowering the doses of cytotoxic compounds [136]. Functionalized IONPs as a carrier can deliver a wide range of drugs to all areas in the body. Hence the efficient intracellular delivery of NPs is one of the main factors in enhancing the efficacy of the encapsulation therapeutic agent. Generally, magnetic IONPs are used as the core and biocompatible components act as a functionalized shell to form the core- shell structure for TDD carriers, and the drugs are bound or encapsulated into the polymer matrix. In a drug carrier system, the sizes, surface properties, and stability are the crucial features.

Partially, the IONPs should be small enough to penetrate through the capillary bed. However, if the diameter of the IONPs is smaller than $10 \mathrm{~nm}$, they will be rapidly removed trough extravasations and renal clearance. Therefore, IONPs with a diameter ranging from 10 to $100 \mathrm{~nm}$ are optimal for intravenous injection and have the most prolonged blood circulation times. Additionally, IONPs with a positive charge are better internalized by human breast cancer cells than those IONPs with a negative charge. However, intake of these IONPs also depends upon cell type. IONPs with a hydrophobic surface are easily absorbed at the protein surface and show a low circulation time [137]. Hence, many biocompatibility materials have been used to functionalize IONPs for TDD, such as biocompatible organic polymers (PEG, chitosan, dextran, etc), liposomes, silica, and bioceramics.

Another important kind of application of functionalized IONPs is in vitro application (such as biosensor, cell bioseparation), which promises increased sensitivity, speed, and cost effectiveness [144-149]. There are several promising nanocomposites for in vitro application, such as Au NPs, and quantum dots (QDs). There are already in vitro diagnostic products on the market, based on magnetic IONPs. In summary, the biocompatibility and toxicity of IONPs are important criteria to take into account for their biomedical applications. Parameters determining biocompatibility and toxicity are the nature of the magnetically responsive component, and the final size of the composite particles including their core and the coatings (shell). Ideally, composite IONPs must also have a high magnetization so that their movement in the blood can be controlled with an external magnetic field until it is immobilized close to the targeted pathologic tissue [150]. Magnetic IONPs with a long blood retention time, biodegradability and low toxicity have emerged as one of the primary nanomaterials for biomedical applications in vitro and in vivo. Some biomedical applications require surface functionalized, especially core shell type, magnetic IONPs. 


\section{Conclusion}

Typical nanoparticle synthesis methodologies involve routes including precipitation, sol-gel, hydrothermal, dry vapor deposition, surfactant mediation, microemulsion, electrodeposition and sonochemical. The electrochemical methods present some advantages over other methods, the crucial one being the high purity of the product, and the control of particle size which is achieved by adjusting the current or the potential applied to the system [151,152]. The size, size distribution, and shape of IONPs are the important parameters influencing the pharmacokinetic and bio-distribution in vivo applications [153]. However, absolute control over the shape and size distribution of magnetic IONPs remains a challenge, and the different formation mechanisms of iron oxides under different conditions still need to be investigated. Furthermore, the ligands and functional layers are often comparable in size to the IONPs, and their coupling effect can significantly increase the hydrodynamic size. Consequently, the increasing hydrodynamic diameter contributes to the macrophage and systemic clearance of functionalized IONPs. Therefore, it is necessary to measure the hydrodynamic diameter and zeta potential of IONPs before and after functionalization. Moreover, bio-distribution is also related to the IONP size and final colloid stability, which determines the fate of IONPs in in vivo and in vitro applications. Mitragotri and Lahann already concluded the size dependent processes of NP transport in the human body, and the optimal hydrodynamic diameter range for in vivo application of intravenously injected NPs is $10-100 \mathrm{~nm}[154,155]$.

In addition, the surface properties of IONPs such as surface charge play an important role in the physical stability and influence the interaction of IONPs with the biological system and their safety. In general, positively charged IONPs interacting strongly with blood components undergo relatively rapid clearance from systemic circulation, leading to nonspecific tissue uptake. In contrast, negatively and neutrally charged IONPs show lower interaction with plasma proteins than positively charged IONPs, and tend to nonspecifically stick to the cells [156]. Furthermore, studies on the influence of the thickness of the functional layer, dispersant packing density, and dispersant conformation on the protein resistance of sterically stabilized IONPs have to be designed carefully to make sure that the right outcomes are arrived at. Though magnetic IONPs exhibit many unique properties which endow various advantages and opportunities in biomedical applications, more toxicological research is needed on the as- synthesized IONPs, and the criteria to evaluate toxicity need to be clearly defined $[157,158]$. For future studies, the use of better and faster methods to improve our understanding of nanoparticle toxicity mechanisms should greatly advance the field [159]. Additionally, the biocompatibility of IONPs is linked to both the intrinsic toxicity of functional layers and its biodegradation metabolites, and to the immune system response following its administration. Importantly, when associated with functional layers, the toxicity profile of the
IONPs may be increased or decreased as a consequence of the modification of their cell/tissue biodistribution and clearance/ metabolization. Accumulation may, indeed, occur in biological sanctuaries where IONPs cannot diffuse when administered alone.

The successful engineering of multifunctional NPs would be of particular interest for the development of theranostic nanomedicine. However, the challenge remains in the clinical translation of nanoparticle probes, and issues such as biocompatibility, toxicity, in vivo and in vitro targeting efficiency, and long-term stability of the functionalized IONPs need to be addressed [160]. It is also desirable that the magnetic nanocrystals should receive much attention as these are now emerging in biomedical applications with new possibilities.

\section{References}

1. C Buzea, I Pacheco, K Robbie (2007) Nanomaterials and nanoparticles: sources and toxicity. Biointerphases 2(4): MR17-MR71.

2. BD Fahlman (2007) Nanoparticles in Drug Delivery and Cancer Therapy: The Giant Rats Tail. Materials Chemistry 2(3): 282-283.

3. RM Cornell, U Schwertmann (1996) The Iron Oxides: Structure, Properties, Reactions, Occurrence and Uses / RM Cornell, U Schwertmann. New York, USA.

4. T Miyata, Y Ishino, T Hirashima (1978) Synthesis 834-835.

5. MP Sharrock, RE Bodnar (1985) J Appl Phys 57: 3919.

6. CR Catlow, J Corish, J Hennesy, WC Mackrod (1988) Atomistic Simulation of Defect Structures and Ion Transport in $\alpha-\mathrm{Fe}_{2} \mathrm{O}_{3}$ and $\alpha-\mathrm{Cr}_{2} \mathrm{O}_{3}$. J Am Ceram Soc 71(1): 42-49.

7. U Schwertmann, RM Taylor (1989) In Minerals in Soil Environments. Dixon J B, Weed SB (Eds.) (2 ${ }^{\text {nd }}$ edn.) Soil Sci Soc Am J, Medison, Wisconsin, USA, pp. 379-438.

8. C Sestier, MF Dasilva, D Sabolovic, J Roses, JN Pons (1998) Electrophoresis 19: 1220-1226.

9. KH Choo, SK Kang (2003) Removal of residual organic matter from secondary effluent by iron oxides adsorption. Desalination 154: 139146.

10. K Raj, R Moskovitz (1990) Commercial applications of ferrofluids. J MagnetMagnetMater 85(1-3): 233-245.

11. BR Pieters, RA Williams, C Webb (1992) In Colloid and Surface Engineering Applications in the Process Industries. p. 248.

12.S Sun, JL Dorman, D Fiorani (1992) Magnetic Properties of Fine Particles.

13. RF Ziolo, EP Giannelis, BA Weinstein, BN Ganguly, V Mehrotra, et al. (1992) Matrix-Mediated Synthesis of Nanocrystalline ggr- $\mathrm{Fe}_{2} \mathrm{O}_{3}$ : A New Optically Transparent Magnetic Material. Science 257: 219-223.

14. I Safarik (1995) Removal of organic polycyclic compounds from water solutions with a magnetic chitosan based sorbent bearing copper phthalocyanine dye. Water Res 29: 101-105.

15. U Häfeli, W Schütt, J Teller, M Zborowski (1997) Scientific and Clinical Applications of Magnetic Carriers. Plenum Press, New York, USA.

16.W Schütt, C Grüttner, U Häfeli, M Zborowski, J Teller, et al. (1997) Hybridoma 16: 109-117.

17. F Gazeau, JC Bacri, F Gendron, R Perzynski, L Raikher, et al. (1998) J Magnet Magnet Mater 186: 175-187. 
18. A Denizli, R Say (2001) J Biomater Sci Polym Edn 12: 1059-1073.

19. S Silber, E Reuter, A Stuttgen, G Albrecht (2002) Prog Org Coat 45: 259266.

20. P Majewski, B Thierry (2007) Functionalized Magnetite Nanoparticles. Crit Rev Solid State Mater Sci 32: 203-215.

21. P Tartaj, MP Morales, Carreno TG, Verdagner SV, CJ Serna (2005) J Magnet Magnet Mater 290: 28-34.

22. MA Uddin, H Tsuda, S Wu, E Sasaoka (2008) Catalytic decomposition of biomass tars with iron oxide catalysts. Fuel 87: 451-459.

23. C Li, Y Shen, M Jias, S Sheng, MO Adebajo, et al. (2008) Catal Commun 9(3): 355-361.

24. F Shi, MK Tse, MM Pohl, A Bruckner, SM Zhang, et al. (2007) Ange Chem 46: 8866-8868

25. CT Wang, RJ Willey (1998) Synthesis and Characterization of Iron Oxide Nanoparticles Supported on Ziconia and Its Application in the Gas-Phase Oxidation of Cyclohexanol to Cyclohexanone. J Non-Crystal Solids 225: 173-177.

26. Q Liu, Z M Cui, Z Ma, SW Bian, WG Song, et al. (2007) Nanotech 118: 37-45.

27. JH Meg, GQ Yang, LM Yan, XY Wang (2005) J Dyes Pigments 66: 109115.

28. D Mohan, CU Pittmang (2007) J Hazard Mater 142: 1-53.

29. D Mohan, CU Pittmang (2006) J Hazard Mater 137: 762-811.

30. NJ Tang, W Zhang, HY Jiang, XL Wu, W Lio, et al. (2004) J Magnet Magnet Mater 282: 92-95.

31. S Ni, X Wang, G Zhou, F Yang, J Wang, et al. (2009) J Mater Letter 63: 2701-2703.

32. K He, CY Xu, L Zhen, WZ Shao (2007) Hydrothermal synthesis and characterization of single-crystalline $\mathrm{Fe}_{3} \mathrm{O}_{4}$ nanowires with high aspect ratio and uniformity. J Mater Letter 61(14-15): 3159-3162.

33. A Ljinas, R Brucas, V Stankus, J Dudonis (2005) J Mater Sci Eng 25: 586590 .

34. H Karami (2010) Synthesis and Characterization of Iron Oxide Nanoparticles by Solid State Chemical Reaction Method. J Clust Sci 21: 11-20.

35. D Chen, S Ni, Z Chen (2007) J China Partimology 5: 357-358.

36. WS Chin, S Rodiman, MH Abdullah, PS Khiew, NM Huang, et al. (2007) J Mater Chen Phys 106: 231-235.

37. AB Chin, II Yaacob (2007) Synthesis and Characterization of Magnetic Iron Oxide Nanoparticles via w/o Microemulsion and Massart's Procedure. 191: 235-237.

38. RA Khaydarov, RR Khaydarov, O Gajurova, Y Estrin, T Scheper (2009) J Nanopart Res 11: 1193-1200.

39. M Lai, JH Lim, S Mubeen, Y Rhum, A Mulchandani, et al. (2009) J Nanotech 20: 185602-185607.

40. KL Chen, CJ Huang, PH Chin, YH Wang (2010) J Key Eng Mater 435: 434-440.

41. H Karami, A Yaghoobi, A Ramezani (2010) Int J Electrochem Sci 5 1046-1059.

42. T Gao, G Meng, Y Wang, S Sun, L Zhang (2002) Electrochemical synthesis of copper nanowires. J Phys Condens Matter 14: 355-360.

43. M Mazur (2004) Electrochemically prepared silver nanoflakes and nanowires. Electrochem Commun 6(4): 400-403.
44. XH Lu, WX Zhao, GR Li, H Hong, Y Tong (2008) J Mater Lett 62: 42804285.

45. J Zhang, LB Kong, H Li, YC Luo, LK ang (2010) J Mater Sci 45: $1947-$ 1954.

46. IJ Shon, HJ Park, KS Nam, KT Lu (2008) J Ceramic Process Res 9: 325329.

47. H Karami, M Alipour (2009) Int J Electrochem Sci 4: 1521-1527.

48. H Karami, B Kafi, SN Mortazavi (2009) Int Electrochem Sci 4: 414-424.

49. H Karami, A Kaboli (2010) Pulsed Current Electrochemical Synthesis of Cadmium Sulfide Nanofibers. Int J Electrochem Sci 5: 706-719.

50. H Karami, E Mohammadzadeh (2010) Synthesis of Cobalt Nanorods by the Pulsed Current Electrochemical Method. Int J Electrochem Sci 5: 1032-1045.

51. H Karami, Ostadkalaych OR (2009) J Clust Sci 20: 587-600.

52. Cardoso JASB, Cardoso DSP, Amaral L, Metin Ö, M Sevim, et al. (2017) Reduced graphene oxide assembled Pd-based nanoalloys for hydrogen evolution reaction. Int J Hydrogen Energy 42: 3916-3925.

53. B Sljukić, DMF Santos, M Vujković, L Amaral, RP Rocha, et al. (2016) Molybdenum Carbide Nanoparticles on Carbon Nanotubes and Carbon Xerogel: Low-Cost Cathodes for Hydrogen Production by Alkaline Water Electrolysis. Chem Sus Chem 9(10): 1200-1208.

54. B Sljukić, M Vujković, L Amaral, DMF Santos, RP Rocha, et al. (2015) Carbon-supported $\mathrm{MO}_{2} \mathrm{C}$ electrocatalysts for hydrogen evolution reaction. J Mater Chem 3: 15505-15512.

55. M Martins, B Sljukić, CAC Sequeira, GSP Soylu, AB Yurtcan, et al. (2018) Appl Surf Sci 428: 31-40.

56. B Sljukić, M Martins, E Kayhan, A Balciunaité, T Sener, et al. (2017) $\mathrm{SnO}_{2}-\mathrm{C}$ supported $\mathrm{PdNi}$ nanoparticles for oxygen reduction and borohydride oxidation. J Electroanal Chem 797: 23-30.

57. M Martins, B Sljukić, Ö Metin, M Sevim, T Sener, et al. (2017) J Alloys \& Compds 718: 204-214.

58. J Milikić, I Stosevskć, J Kristić, S Miljanić, B Sljukić, et al. (2017) J Anal Methods Chem 9.

59. J Milikić, G Cirić Marjanović, S Mentus, DMF Santos, CA Sequeira, et al. (2016) Electrochim Acta 213: 298-305.

60. M Martins, B Sljukić, CA Sequeira, Ö Metin, M Erdem, et al. (2016) Biobased carbon-supported palladium electrocatalysts for borohydride fuel cells. Int J Hydrogen Energy 41(25): 10914-10922.

61. JASB Cardoso, B Sljukić, M Erdem, CAC Sequeira, DMF Santos (2018) Catalysts 8: 49-62.

62. J Stosevski, J Krstic, J Milikc, B Sljukić, Z Kacarević Popović, et al. (2016) Energy 101: 79-90.

63. B Sljukić, M Vujković, L Amaral, DMF Santos, RP Rocha, et al. (2015) Carbon-supported $\mathrm{MO}_{2} \mathrm{C}$ electrocatalysts for hydrogen evolution reaction. J Mat Chem A3: 15505-15512.

64. B Sljukić, J Milikić, DMF Santos, CA Sequeira (2013) Carbon-supported $\mathrm{Pt}_{0.75} \mathrm{M}_{0.25}(\mathrm{M}=\mathrm{Ni}$ or $\mathrm{Co})$ electrocatalysts for borohydride oxidation. Electrochim Acta 107: 577-583.

65. AL Morais, JRC Salgado, B Sljukić, DMF Santos, CAC Sequeira (2012) Electrochemical behaviour of carbon supported Pt electrocatalysts for $\mathrm{H}_{2} \mathrm{O}_{2}$ reduction. Int J Hydrogen Energy 37: 14143-14151.

66.J Ordoukhanian, H Karami, A Nezhadali (2016) One step paired electrochemical synthesis of iron and iron oxide nanoparticles. Mat Sci-Poland 34: 655-658. 
67. AJ Bard, LR Faulkner (2001) Electrochemical Methods. Fundamentals and Applications. John Wiley \& Son, Texas, USA.

68. DF Shriver, PW Alkins (1990) Inorganic Chemistry. Oxford University Press, Oxford, USA.

69. KI Popov, SS Djokic, BN Grgur (2002) Fundamental Aspects of Electrometallurgy. Kluwer Academic/Plenum Publishers, New York, USA.

70. MT Beck, B Criszar, P Szarvas (1960) Nature 188: 846.

71. E Raub, K Müller (1967) Fundamentals of Metal Deposition.

72. M Schlesinger, M Paunovic (2000) Modern Electroplating. John Wiley, New York, USA.

73. PM Vereecken, RA Binstead, H Deligianni, PC Andricacos (2005) The chemistry of additives in damascene copper plating. IBMJ Res Develop 49: 3-18.

74. TP Moffat, D Wheeler, D Josell (2004) Electrodeposition of Copper in the SPS-PEG-Cl Additive System. J Electrochem Soc 151: 262-271.

75. IA Carlos, CAC Souza, EMJA Pallone, RHP Francisco, V Cardoso, et al. (2000) Effect of tartrate on the morphological characteristics of the copper-tin electrodeposits from a noncyanide acid bath. J Appl Electrochem 30: 987-994.

76. K Nakaoka, K Ogura (2002) Electrochemical Preparation of p-Type Cupric and Cuprous Oxides on Platinum and Gold Substrates from Copper (II) Solutions with Various Amino Acids. J Electrochem Soc 149: 579-585.

77. JA Switzer, HM Kothari, EW Bohannan (2002) Thermodynamic to Kinetic Transition in Epitaxial Electrodeposition. J Phys Chem B 106: 4027-4031.

78. M Nobial, O Devos, OR Mattos, B Tribollet (2007) The nitrate reduction process: A way for increasing interfacial pH. J Electroanal Chem 600: 87-94.

79. A Seshadri, NR De Tacconi, CR Chenthamarakshan, K Rajeshwar (2006) Electrochem Sol St Letters 9:

80. M Izaki, T Omi (1996) J Electrochem Soc 143: 53.

81. Y Zhou, JA Switzer (1996) Growth of cerium (IV) oxide films by the electrochemical generation of base method. J Alloys Compds 237: 1-5.

82. H Natter, M Schmelzer, S Janssen, R Hempelmann (1997) Phys Chem Chem Phys 101: 1706.

83. A Dierstein, H Natter, F Meyer, HO Stephan, C Kropf, et al. (2001) Scripta Materialia 44: 2209.

84. E Gomez, A Labarta, A Llorente, E Valles (2002) Surf Coat Technol 153: 261.

85. C Bonhote, D Landolt (1997) Electrochim Acta 42: 2407.

86. Q Li, EC Walter, BJ Murray, JT Newber, EW Bohannan, et al. (2005) Molybdenum Disulfide Nanowires and Nanoribbons by Electrochemical/Chemical Synthesis. J Phys Chem B 109(8): 31693182.

87. ML Varsonyi, A Miko, LK Varga, E Kalman (2005) Corros Sci 47: 681.

88. M Knez, K Nielsch, L Niinisto (2007) Synthesis and Surface Engineering of Complex Nanostructures by Atomic Layer Deposition. Adv Mater 19(21): 3425-3438.

89. S Sakai, S Nakanishi, Y Nakato (2006) J Phys Chem B 110: 11944.

90. M Starowicz (2011) Electrochemical synthesis of magnetic iron oxide nanoparticles with controlled size. J Nanopart Res 13(12): 7167-7176.

91. D Gogi, MT Ansari, L Kabitha (2016) Arabian J Chem 305-310.
92. Ö Ozdemir, DJ Dunlop, BM Moskowitz (2002) Changes in remanence, coercivity and domain state at low temperature in magnetite. Earth Planet Sci Lett 194(3-4): 343-358.

93. S Franger, P Berthet, K Berthon (2004) Electrochemical synthesis of $\mathrm{Fe}_{3} \mathrm{O}_{4}$ nanoparticles in alkaline aqueous solutions containing complexing agents. J Solid State Electrochem 8(4): 218-223.

94. M Ibrahim (2009) Electro-precipitation of magnetite nanoparticles: An electrochemical study. Electrochim Acta 55(1): 155-158.

95. L Martinez, D Linen, F Martin, M Gabas, E Qualgliata, et al. (2007) J Electrochem Soc 154: D126-D133.

96. D Carlier, C Terrier, C Arm, JP Anserment (2005) Preparation and Magnetic Properties of $\mathrm{Fe}_{3} \mathrm{O}_{4}$ Nanostructures Grown by Electrodeposition. Electrochem Sol State Lett 8(3): C43-C46.

97. T Sorenson, SA Morton, GD Waddill, JA Switzer (2002) Epitaxial Electrodeposition of $\mathrm{Fe}_{3} \mathrm{O}_{4}$ Thin Films on the Low-Index Planes of Gold. J Am Chem Soc 124(25): 7604-7609.

98. S Chatman, AJG Noel, KM Poduska (2005) J Appl Phys 98: 113902-1113902-6.

99. LY Zhang, DS Xue, XF Xu, AB Gui, CX Gao (2004) The fabrication and magnetic properties of nanowire-like iron oxide. J Phys Condens Matter 16: 4541-4548.

100. MP Nikiforov, A Vertegel, MG Shumsky, JA Switzer (2000) Epitaxial Electrodeposition of $\mathrm{Fe}_{3} \mathrm{O}_{4}$ on Single-Crystal $\mathrm{Au}(111)$ Adv Maters 12: 1351-1353.

101. G Zolti, G Schiavan, S Zecchin (1998) J Electrochem Soc 145: 385-389.

102. R Schrebler, K Bello, F Vera, P Cury, E Munoz, et al. (2006) Electrochem Sol State Lett 9: C110-C113.

103. C Pascal, JL Pascal, F Faviur (1999) Electrochemical Synthesis for the Control of $\gamma-\mathrm{Fe}_{2} \mathrm{O}_{3}$ Nanoparticle Size. Morphology, Microstructure, and Magnetic Behavior. Chem Mater 11: 141-147.

104. H Karami, E Chidar (2012) Pulsed-Electrochemical Synthesis and Characterizations of Magnetite Nanorods. Int J Electrochem Sci 7: 2077-2090.

105. J Ordoukhanian, H Karami, A Nezhadali (2015) Ceramics International 41: 14760-14765.

106. M Aghazadeh, MR Ganjali (2017) J Mater Sci Mater Electron 28: 8144.

107. G Oskam, PM Vereecken, X Shao, J Fransaer (2010) Semiconductors, Metal Oxides, and Composites: Metallization and Electrodeposition of Thin Films and Nanostructures. ECS Transactions 25(27).

108. MC Chandrasekas, M Pushjavanam (2008) Electrochim Acta 53: 3313-3322.

109. MP Parolave, MM Hernandez, I Gonzalez, N Batina (1998) Surface Science 399: 80.

110. CJ Clarke, GJ Browning, SW Donne (2006) An RDE and RRDE study into the electrodeposition of manganese dioxide. Electrochim Acta 51: 5773-5784.

111. DA Buttry, MD Ward (1992) Measurement of interfacial processes at electrode surfaces with the electrochemical quartz crystal microbalance. Chem Rev 92: 1355-1379.

112. MT Neshkova, V Nikolova, V Petrov (2006) New real-time analytical applications of electrochemical quartz crystal microbalance Stoichiometry and phase composition monitoring of electrodeposited thin chalcogenide films. Anal Chim Acta 34: 573-574.

113. RP Raffaelle, TD Golden, RJ Philips, JA Switzer (1993) Nanostructure Materials 2: 175. 
114. D Faivre (2016) Iron Oxides: From Nature to Applications, WileyVCH, New York, USA.

115. R Hufschmid, H Arami, KM Krishnan, ND Browning (2015) Microsa Microanal 21: 965-966.

116. O Khaselev, JM Sykes (1997) In-situ electrochemical scanning tunneling microscopy studies on the oxidation of iron in alkaline solution. Electrochim Acta 42(15): 2333-2337.

117. OE Husser, DH Craston, AJ Bard (1989) J Electrochem Soc 136: 3222

118. B Losiewiez, M Popezyk, A Smolka, M Szklarska, P Osak, et al. (2015) Solid State Phenomena 228: 394-409.

119. S Hogmark, S Jacobsson, AK Rudolphi (1998) Materialvetenskop.

120. Nong M, Hwang (2016) Non-Classical Crystallization of Thin Films and Nanostructures in CVD and DVD Processes. Springer, Netherlands.

121. FN Sayed, V Polshettiwar (2015) Facile and Sustainable Synthesis of Shaped Iron Oxide Nanoparticles: Effect of Iron Precursor Salts on the Shapes of Iron Oxides. Sci Rep 5: 9733.

122. M Imafuku, M Kurosaki, K Kawesaki (1998) J Synchrotron Radiation 5: 935.

123. G Hägg (1989) Allmänn och oorganisk Kemi.

124. AR West (1984) Basic Solid State Chemistry.

125. DI Jerdev, BE Koel (2002) Surface Science 513: L391-L396.

126. DR Baer, DJ Gaspar, P Nachimuthu, SD Techane, DG Castner (2010) Application of surface chemical analysis tools for characterization of nanoparticles. Anal Bioanal Chem 396: 983-1002.

127. JR Ferraro, K Nakamoto (1994) Introductory Raman Spectroscopy. Academic Press, San Diego, USA.

128. S Mosivaned, LM Monzon, I Kazeminezhad, JM Coey (2013) Influence of Growth Conditions on Magnetite Nanoparticles ElectroCrystallized in the Presence of Organic Molecules. Int J Mol Sci 14: 10383-10396.

129. RMA Azzam, NM Bashara (1977) Ellipsometry and Polarized Light North-Holland, New York, USA.

130. YI Kuznetsov, NP Andreeva, NP Sokolova, RA Bulgakova (2003) Joint Adsorption of Oleic and Phenylanthranilic Acids at Passive Iron Prot Metals 39: 462- 467.

131. YI Kuznetsov (2016) Organic corrosion inhibitors: where are we now? A review. Part II. Passivation and the role of chemical structure of carboxylates. Int J Corros Scale Inhib 5: 282-318.

132. MM Lin, H Kim, M Mohammad (2010) Nano Reviews 1: 1-17.

133. X Peng, H Chen, J Huang, H Mao, DM Shin (2011) Biomedical Engineering. From Theory to Applications.

134. M Arruebo, R Fernandéz-Pacheco, MR Ibarra, J Santamaria (2007) Magnetic nanoparticles for drug delivery. Nano Today 2: 22-32.

135. JD Durán, JL Arias, V Gallardo, AV Delgado (2008) Magnetic colloids as drug vehicles. J Pharm Sci 97: 2948-2983.

136. SW Cao, YJ Zhu, MY Ma, L Li, L Zhang (2008) Hierarchically Nanostructured Magnetic Hollow Spheres of $\mathrm{Fe}_{3} \mathrm{O}_{4}$ and $\gamma-\mathrm{Fe}_{2} \mathrm{O}_{3}$ : Preparation and Potential Application in Drug Delivery. J Phys Chem C 112: 1851-1856.

137. L Wahajuddin, S Arora (2012) Superparamagnetic iron oxide nanoparticles: magnetic nanoplatforms as drug carriers. Int J Nanomed 7: 3445-3471.
138. SS Banerjee, DH Chen (2010) Int J Appl Ceram Technol 7: 111.

139. G Hasenpusch (2012) Magnetized aerosols comprising superparamagnetic iron oxide nanoparticles improve targeted drug and gene delivery to the lung. Pharm Res 29(5): 1308-1318.

140. Q Wan (2013) Nanoscale 5: 744.

141. X Zhu, J Yuan, K Leung, S Lee, K Sham, et al. (2012) Nanoscale 4: 5744.

142. XL Liu, HM Fan, JB Yi, Y Yang, ESG Choo, et al. (2012) Optimization of surface coating on $\mathrm{Fe}_{3} \mathrm{O}_{4}$ nanoparticles for high performance magnetic hyperthermia agents. J Mater Chem 22: 8235-8244.

143. S Balivada (2010) A/C magnetic hyperthermia of melanoma mediated by iron(0)/iron oxide core/shell magnetic nanoparticles: a mouse study. BMC Cancer 10: 119.

144. DD Shao, KK Xu, XJ Song, JH Hu, WL Yang, et al. (2009) J Colloid Interface Sci 336: 526.

145. F Chen, RB Shi, Y Xue, L Chen, QH Wan (2010) J Magn Magn Mater 322: 2439.

146. CL Du, W Du, B Wang, WY Feng, Z Wang, et al. (2010) Chim J Anal Chem 38: 902.

147. HD Wu, H Qian, ZJ Yu, WH Ye (2010) Acta Polym Sin 1238.

148. AH Latham, ME Williams (2008) Controlling transport and chemical functionality of magnetic nanoparticles. Acc Chem Res 41: 411-420.

149. JH Chang, J Lee, Y Jeong, JH Lee, IJ Kim, et al. (2010) Hydrophobic partitioning approach to efficient protein separation with magnetic nanoparticles. Anal Biochem 405: 135-137.

150. M Mahmoudi, S Sant, B Wang, S Laurent, T Sen (2011) Superparamagnetic iron oxide nanoparticles (SPIONs): development, surface modification and applications in chemotherapy. Adv Drug Delivery Rev 63: 24-46.

151. L Cabrera, S Gutierrez, N Menendez, MP Morales, P Herrasti (2008) Magnetite nanoparticles: electrochemical synthesis and characterization. Electrochim Acta 53: 3436-3441.

152. AR López, AP Arroyo, JM Gomez, CE Arteaga, JJ Rivera, et al. (2012) J Nanopart Res 14: 993.

153. VR Devadasu, V Bhardwaj, MNVR Kumar (2013) Can controversial nanotechnology promise drug delivery? Chem Rev 113: 1686-1735.

154. S Mitragotri, J Lahann (2009) Physical approaches to biomaterial design. Nat Mater 8: 15-23.

155. E Amstad, M Textor, E Reimhult (2011) Stabilization and functionalization of iron oxide nanoparticles for biomedical applications. Nanoscale 3: 2819-2843.

156. LH Reddy, JL Arias, J Nicolas, P Couvreur (2012) Magnetic nanoparticles: design and characterization, toxicity and biocompatibility, pharmaceutical and biomedical applications. Chem Rev 112: 5818-5878.

157. CJ Rivet, Y Yuan, DA Borca-Tasciue, RJ Gilbert (2012) Altering iron oxide nanoparticle surface properties induce cortical neuron cytotoxicity. Chem Res Toxicol 25: 153-161.

158. M Mahmoudi, H Hofmann, B Rotheu-Rutishauser, A Petri-Fink (2012) Assessing the in vitro and in vivo toxicity of superparamagnetic iron oxide nanoparticles. Chem Rev 112: 2323-2338.

159. S Laurent, D Forge, M Port, A Roch, C Robic, et al. (2010) Chem Rev 110: 2574 .

160. E Terreno, DD Castelli, A Viale, S Aime (2010) Challenges for Molecular Magnetic Resonance Imaging. Chem Rev 110: 3019-3024. 
This work is licensed under Creative Commons Attribution 4.0 License

DOI: 10.19080/OMCIJ.2018.05.555660
Your next submission with Juniper Publishers will reach you the below assets

- Quality Editorial service

- Swift Peer Review

- Reprints availability

- E-prints Service

- Manuscript Podcast for convenient understanding

- Global attainment for your research

- Manuscript accessibility in different formats

( Pdf, E-pub, Full Text, Audio)

- Unceasing customer service

Track the below URL for one-step submission https://juniperpublishers.com/online-submission.php 